\title{
Pacific island tropical cyclones are more frequent and globally relevant, yet less studied
}

\author{
Thomas E. Marler* \\ Western Pacific Tropical Research Center, College of Natural and Applied Sciences, University of Guam, Mangilao, GU, USA
}

\section{Edited by:}

Govindasamy Agoramoorthy, Tajen

University, Taiwan

\section{Reviewed by:}

Nathaniel Kenneth Newlands,

Federal Government of Canada,

Canada

Mustafa M. Aral, Georgia Institute of

Technology, USA

*Correspondence:

Thomas E. Marler, Western Pacific Tropical Research Center, College of Natural and Applied Sciences,

University of Guam, 303 University

Drive, UOG Station, Mangilao, GU

96923, USA

e-mail: thomas.marler@gmail.com
Typhoon Haiyan devastated the Philippines in 2013 and illuminates the fact that the majority of tropical cyclone (TC) research has focused on the Atlantic Basin, continental socio-ecological systems, affluent regions where the resilience attributes of the human element differ from that of the of majority the world's population, and organized countries where research and relief capacities are among the best worldwide. I contend that this collective international bias minimizes the usefulness of global TC research in light of global change forecasts, which predict increased frequency of intense TCs. Moreover, paleoecological studies indicate ecosystem resilience following a TC is greatly increased within habitats that experienced a prior history of frequent TCs. When these retrospective and future visions are connected, science-based analysis of the influences of climate change on TC disturbance argues for an increase in contemporary research on TCs of developing island nations in the western Pacific where TCs are already relatively frequent. Otherwise the current research trajectory may further widen the disconnect between best available science and future management decisions.

Keywords: hurricane, tropical cyclone, typhoon, Philippines

\section{BACKGROUND}

Typhoon Haiyan caused excessive damage to human life and natural systems in numerous Philippine islands in November 2013 (Figure 1A), joining the many other typhoons that have devastated western Pacific islands by providing an opportunity to study stochastic disturbances in ways not attainable in controlled experimentation. The need to seize every opportunity to study major tropical cyclones (TCs, typhoons and hurricanes) is underscored by the predicted outcomes of climate and other global changes (Text Box 1). The scientific community has studied climate change by focusing on temperature and moisture changes, but the effects of disturbances caused by climate change have largely been ignored (Dale et al., 2001). Our collective ability to pave the way for appropriate modeling and conservation of threatened resources requires that we better understand intense TC disturbance processes.

Researchers in the Atlantic hurricane zone have capitalized on opportunities to study major TCs, which has resulted in a plethora of scientific studies published in myriad journals. The value of similar research from the Pacific TC hotspot is arguably more beneficial to future global issues.

(1) Recurrence is an important trait when valuing where to focus TC research to inform future global concerns. TC frequency in the western Pacific greatly exceeds that in the Atlantic (Lin et al., 2011). For example, within all properties of the United States (U.S.) the Territory of Guam claims the greatest risk of being impacted by a TC (Marler, 2001). To illustrate, Typhoon Omar devastated Guam in August 1992 when Hurricane Andrew impacted Florida. Southern Florida experienced 12 subsequent years of freedom from TC winds until 2004's Hurricane Charley. In contrast, Guam was devastated by four more TCs before the end of 1992. Similarly, nine to 10 TCs strike the Philippines annually (www.maybagyo. com) and three to four strike Taiwan annually (Wu and Kuo, 1999). To compare, the extensive Puerto Rico Luquillo Experimental Forest TC research program (Walker et al., 1996; Willig et al., 2011) has been based on two TCs in the past 20 years. Studying Pacific TCs would more fully meet future needs based solely on contemporary TC frequency.

(2) Accumulated cyclone energy (ACE) is founded on the square of the wind speed recorded every $6 \mathrm{~h}$ during the life of TCs (Bell et al., 2000), and integrates destructive potential more accurately than TC frequency alone. A comparison of 40 years of ACE epitomizes the value of the western Pacific region for studying TCs (Figure 1B), in that mean of the western Pacific greatly exceeded that of the Atlantic.

(3) Paleoecological research indicates localities with a history of TCs exhibit greater TC resilience than localities with less frequent TCs (Cole et al., 2014). The authors indicate the systems evolved as a unit to frequent disturbances. Studying ecosystem damage and recovery in the Pacific arguably informs the anticipated climate normals of the future, and studying the same in the Atlantic produces outcomes that lack relevance to future ecosystems after those systems have adapted to increased TC frequency.

(4) The vast majority of the scientific publications in the Atlantic hurricane zone have come from continental habitats. Islands interact with TCs in a manner that is distinct from how continental land mass interacts with TCs (Text Box 2), and 

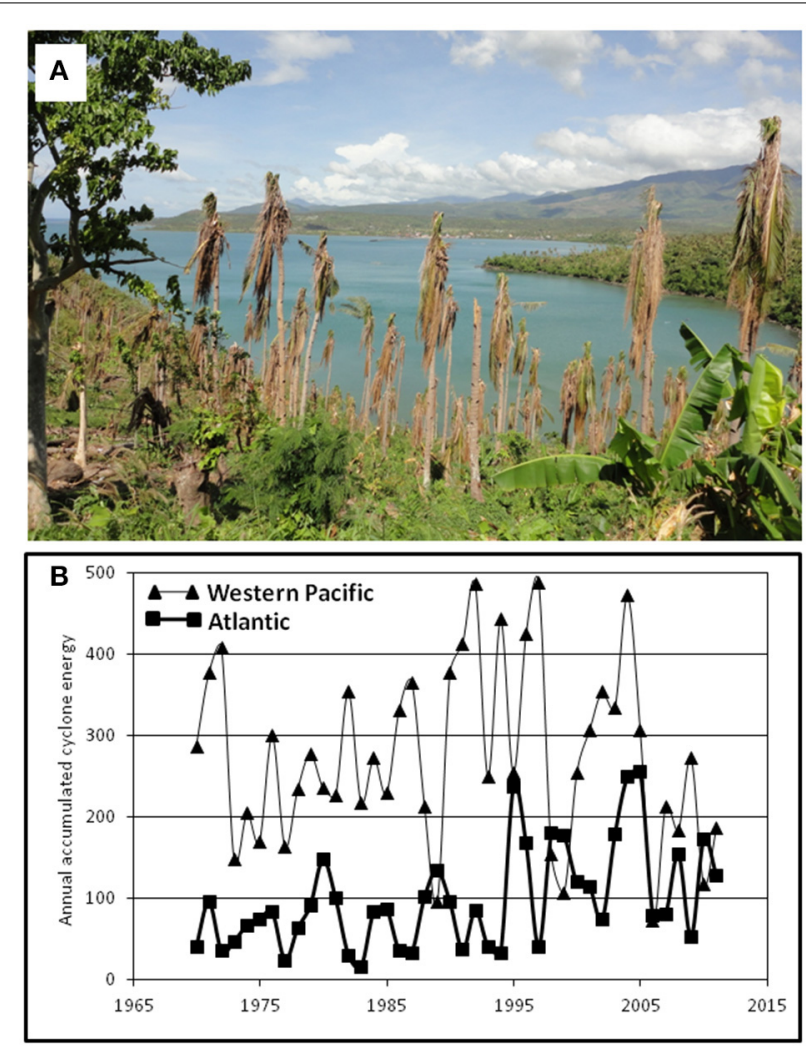

FIGURE 1 | (A) This copra agroforestry system in Leyte was devastated by Typhoon Haiyan in November 2013. It illustrates several key issues of tropical cyclones in the western Pacific that deserve greater research focus, including conversion of coastal sites to human use thereby increasing damage to anthropic systems, devastation of food security, and the need for livelihood restoration. (B) The accumulated cyclone energy per year (knots $^{2} * 10,000$ ) for the Western Pacific region and the Atlantic region.

much of the Atlantic information does not inform facets of island TCs. This includes the Luquillo Experimental Forest, as it contains no coastal environments. A high percentage of global environments that are susceptible to TCs are from islands, and studying Pacific TCs would be more instructive for meeting their needs.

(5) Cultural and socioeconomic traits of western Pacific islands align with a higher proportion of the world's population than those traits of U.S. residents where most of the Atlantic hurricanes have been studied. Studying socio-ecological issues of Pacific TCs would be more informative for meeting global needs based solely on this disparity in social and economic status of affected populations.

(6) Sub-national relief capability is substantial in the U.S. and national relief capacity is among the best worldwide. On the contrary, most of the Pacific nations that experience TCs exhibit compromised relief and research capacities. Therefore, coordination of international relief contributions is less needed for most Atlantic TCs than Pacific TCs. Studying Pacific island TCs would be more informative for improving future relief efforts than studying Atlantic continental TCs.

\section{GLOBAL PRIORITIZATION}

If climate change predictions are accurate and more frequent intense TCs will characterize future years (Text Box 1), contemporary research designed to address global priorities should clearly be maximized in the Pacific. If paleoecological retrospections are accurate (Cole et al., 2014) and ecosystems that have experienced frequent TCs exhibit greater resilience than ecosystems that are naïve with respect to TCs, the value of contemporary research in the Atlantic is highly compromised in regards to informing the future. Based on relative global value alone, one would expect a rich history of publications on Pacific island TCs. Unfortunately, the opposite is the reality.

A recent Google Scholar search indicated the 22 years of research since Hurricane Andrew in Florida (26 direct human casualties in U.S.) generated 69,600 outcomes. Typhoon Thelma struck the Philippine Islands 9 months earlier $(5100+$ human casualties) and the same search indicated the same 22 years generated 197 outcomes. Quality of research and value for posterity were also contrasting, in that Hurricane Andrew research included human health issues, natural systems responses, climate science contributions, and more; and the results were sequestered in scholarly publications for effectual future acquisition. Typhoon Thelma publications were based on anecdotes, lacking in empirical data or experimental protocols, and appeared in publications that will be difficult or impossible to access in the future.

\section{ISLANDS}

Island biology and ecology have been vital for the study of evolution and many other scientific disciplines. Island ecology is of crucial interest to contemporary biologists, ecologists, and conservationists (Text Box 2). When a TC passes through an island nation, the number of times the eye interacts with a coastline is exceedingly high. The multiple landfall events and resultant storm surge events subject each disjunct habitat to a distinct storm surge event with destruction that supplements wind damage. In turn, research designed to understand socio-ecological system resistance to and resilience following TCs can exploit the numerous disjunct coastal habitats that are disturbed during a single TC event.

Continental land mass is devastating to the strength of a TC after the eye makes landfall (Text Box 2). In contrast, islands such as those affected by Typhoon Haiyan exert only ephemeral influence on TC intensity.

Coastal areas of island nations represent a high proportion of their terrestrial systems. Typhoon Haiyan first impacted Palau, where coastal length in relation to land area is 1655-fold greater than that of the U.S., then impacted the Philippines, where this trait is 61-fold greater than that of the U.S. (Text Box 2). Therefore, the proportion of collective devastation due to coastal damage is exceedingly great for islands and cannot be studied in continental settings. Coastal sites are preferentially used by humans in developing nations with small to medium sized islands (Text Box 2). This phenomenon increases damage to human life and infrastructure when islands are impacted by TCs by increasing risk of exposure (Peduzzi et al., 2012). Similarly, many island plant species are constricted to coastal environments, and sustaining biodiversity in these coastal sites will require 


\section{Text Box 1 | Anthropogenic global change and tropical cyclones.}

Climate change predictions indicate severity of TCs will increase (Emanuel, 2005; Elsner et al., 2010; Knutson et al., 2010; Stocker et al., 2013). Studying today's relatively frequent severe Pacific TCs will uniquely inform the global community in preparation for this future. Studying today's relatively infrequent Atlantic TCs cannot adequately meet this goal.

The El Niño-Southern Oscillation phenomenon affects the genesis, track, duration, and intensity of TCs (Chan, 2000; Camargo and Sobel, 2005; Kim et al., 2011), illuminating one of the mechanisms through which global climate change factors affect TCs.

- Spatial distribution of sea surface temperature warming influences various TC conditions such as favorability of TC landfall events (Clark and Chu, 2002; Kim et al., 2011; Chowdhury et al., 2014), revealing another important mechanism by which human activities affect TCs.

Many TCs transform into midlatitude low-pressure systems at the end of their life. These tropical-extratropical interaction events may modify Rossby-wave trains (Riemer and Jones, 2010), providing another mechanism whereby global change factors may alter the influence of TCs on weather events.

Ecosystem resilience following a TC may be influenced by the timing of the TC in relation to other seasonal events (Marler, 2001). Hsu et al. (2014) discussed the recent changes in the number of Western Pacific catastrophic TCs that have occurred in the late season. Shifts in seasonal occurrence may be yet another mechanism through which future global change factors modify the destructive potential of TCs.

Forest fragmentation is creating more habitats worldwide with insular patches. Contemporary island research can inform our understanding of biology within these future forest fragments as they continue to be created.

- Increased incidence of alien invasions via global change may interact with TCs in unexpected ways. For example, arthropod pests may compromise resistance of native flora to mechanical stress of TCs (Marler, 2013) and resilience following major TC damage (Marler and Lawrence, 2013).

- Small islands by nature are at great risk from many ongoing global changes (Bramwell and Caujapé-Castells, 2011; Connell, 2013).

- Coastal habitats are being preferentially converted for human use during anthropogenic change, leading to increased threats to remaining coastal ecosystems due to species and habitat losses.

\section{Text Box 2 | Islands.}

When a TC passes through an island nation, the number of times the eye interacts with a coastline is surprisingly high. For example, the track of TC Haiyan positioned the eye within $50 \mathrm{~km}$ of 150 + Philippine islands during the few hours that were needed for the TC to cross the country. This does not include Haiyan's landfall events in Palau and continental Asia.

Continental land mass is devastating to strength of a TC after the eye makes landfall. A uni-directional, rapid dissipation of power usually kills the storm within a few hours after landfall. For example, when Hurricane Andrew made landfall in Louisiana it was downgraded to tropical storm status after a few hours and about $200 \mathrm{~km}$. While large islands with extensive elevation may exert some influence on a TC (Bender et al., 1987; Wu and Kuo, 1999), small islands exert minimal, ephemeral influence (Marler, 2001). For example, TC Haiyan initially struck the Philippines at the southern tip of Samar as a Category $\vee$ typhoon, then proceeded to devastate one island after another until $660 \mathrm{~km}$ later it departed the western Philippine islands as a sustained Category $\vee$ typhoon.

Coastal areas of island nations represent a high proportion of their terrestrial systems. A TC that impacts the U.S. affects a country with coastal length in relation to land area of only $2 \mathrm{~m} \mathrm{~km}^{-2}$, but TC Haiyan impacted the Philippines where this trait is $122 \mathrm{~m} \mathrm{~km}$ and Palau where this trait is $3310 \mathrm{~m} \mathrm{~km}^{-2}$ (World Fact book. http://www.cia.gov). Therefore, the proportion of damage due to coastal forms of damage is exceedingly great for islands.

- Coastal sites are preferentially used by humans in developing nations with small to medium sized islands devoid of roads. In the Philippines, $100 \%$ of the human life and infrastructure is located on the coast of many islands. This is not the case for continents. Therefore, $100 \%$ of the island damage to human infrastructure and life occurs on the coast where eyewall intensity is greatest and storm surge is restricted. The conversion of coastal ecosystems to human use and occupation will only worsen (Sales, 2009).

Many island plant species are constricted to coastal environments (Primavera and Sabada, 2012). Sustaining this coastal biodiversity will be more difficult considering the predicted changes in TC activity due to climate change.

- The community types that are damaged by a continental TC are relatively homogeneous compared to island nations like the Philippines. For example, adjacent islands may be highly contrasting in geological age and edaphic origins. Some islands have continental origins and brought with them continental plants and animals during drift (Palawan), some islands formed with tectonic uplifting of the ocean bed (Bohol), and some are volcanic (Leyte). Superimposed on these contrasting geological origins are coral deposits that form karst coastal terrestrial habitats. Therefore, a single island TC event can simultaneously disturb highly contrasting habitats with divergent biodiversity, providing an opportunity to study resistance and resilience in the context of biodiversity and conservation in ways not allowable in continental locations. 
greater research focus if frequency of intense TCs does increase as predicted.

The community type that is damaged by a continental TC is relatively homogeneous compared to that of island nations. This renders island nations of particular value for studying responses to single TC events because adjacent islands may be highly contrasting in geological age, edaphic inceptions, and biodiversity (see Text Box 2).

\section{THE PHILIPPINE ISLANDS}

The global scientific community has evidently not perceived the value in studying Pacific TCs or has allowed logistical, monetary, time, and distance expenses to counter the value that is acknowledged. To illustrate what has been missed as a result of this Atlantic Basin bias, a brief focus on the Philippines may suffice.

The Philippines is considered a mega-diverse country containing a high proportion of global biodiversity and endemism (Mittermeier et al., 1997; Myers et al., 2000; Brooks et al., 2006; Persoon and van Weerd, 2006). More than 20,000 plant and animal species are endemic, and more new mammal species descriptions have occurred in the Philippines in the past decade than any other country. Conservationists are concerned that many of the ultra-endemics will be extinct before they have been described (Sohmer, 2001). Ecologists and biologists studying TCs in the Atlantic Basin have studied forest systems lacking such compelling conservation needs.

The wind speeds, human death toll, numbers of displaced families, and cumulative ecosystem disturbance for Philippine TCs exceed those same metrics for the heavily studied Atlantic TCs. Coping with frequent TCs defines what it means to live in many western Pacific islands. Studying Atlantic socio-ecological systems where confrontations with TCs are not as defining of everyday life cannot foster increased understanding of how disturbances affect everyday life in the Pacific.

The number of global residents living in TC-impacted regions and sharing the cultural and socioeconomic traits of the U.S. residents studied following Atlantic TCs is far less than that of residents in developing island nations like the Philippines. For example, the myriad social science publications following Hurricane Andrew in southern Florida arguably have limited relevance to a majority of the world's residents. Using global standards, the Florida study subjects were privileged, had access to copious disposable resources, and led convenient lives. Their ability or inability to cope with a disaster like a TC that caused 26 direct human deaths would not align with the ability of a Philippine family to cope with a TC like Typhoon Thelma that caused $5100+$ human deaths or Typhoon Haiyan that caused 6300 + deaths, especially considering a high proportion of Philippine families survive on less than US $\$ 2$ per day (Schelzig, 2005) and temporarily lose their only source of income following every major TC. Therefore, a greater proportion of the world's residents would directly benefit from the outcomes of social science research in a developing island nation like the Philippines where food security and livelihood restoration are acute factors during disaster recovery.

The proportion of TC-impacted regions that share climate and geological traits with tropical islands greatly exceeds the proportion that shares those traits with continental coastal areas. Therefore, a greater proportion of the world's ecosystems that will experience future intense TCs would benefit from research in tropical islands rather than subtropical and temperate continental habitats.

\section{EXPANDED RESEARCH VALUE}

Island disturbance research in and of itself has other applications that magnify its value. Oceanic island research has application to all "insular" habitats (MacArthur and Wilson, 1963). Indeed, anthropogenic forest fragmentation is creating disjointed communities that are islands in many respects (Laurence and Bierregaard, 1977). Similarly, terrestrial community resources are rarely available to plants, animals, and microbes in a homogeneous matrix, instead they are available in islands with distinct ecological edges (Porensky and Young, 2013). Therefore, research in oceanic islands directly informs many questions pertinent to other global agendas.

TC research has other applications that amplify its worth. The Philippines experiences more natural hazards than any other country, averaging eight major disasters per year (Bankoff, 2003), including earthquakes, floods, landslides, and volcanic eruptions. A natural large scale disturbance becomes more or less of a disaster for international relief organizations based on many factors other than the natural disturbance that sparked the disaster (Gaillard et al., 2007). The global community would benefit from conducting extensive case studies in disasters like TC Haiyan where dysfunction, confusion, and corruption defined the relief efforts in light of more than one million uninhabitable houses, $28,000+$ injured persons, and 6300+ human deaths (NDRRMC, 2014). Expert vetting to identify causes of the hindrances to successful relief work would improve future international relief efforts to a much greater degree than similar studies of U.S. hurricane relief work. However, if the aftermath of TC Haiyan aligns with that of other recent deadly typhoons in the Philippines, there will be minimal research initiated to address this international need.

The study of extreme weather events such as TCs in relation to climate change is in its infancy (Abeli et al., 2014). More research from the ignored western Pacific TC hotspot would add to the needs for compiling case studies to enable a quantitative analysis to reveal general patterns in extreme weather events.

\section{PRIORITIES}

Pursuing an adequate understanding of the manner in which human and natural systems recover from large scale disturbances in space and time requires theoretical and empirical approaches that focus on the future, not just the present. New methods and models (Peduzzi et al., 2012; Chowdhury et al., 2014) need to be informed by a balanced approach, not a database biased toward the Atlantic. A global ethos in TC research is further validated by the strong link between Pacific and Atlantic activity. For example, El Niño-Southern Oscillation control over TC activity (Text Box 2) affects both TC basins. Additionally, the positioning of heat sinks at ocean depths may affect local ocean heat sequestration dynamics, but it also influences global surface air temperatures (Chen and Tung, 2014; Kintisch, 2014). 
The disparity between Pacific island and Atlantic continental TC research is clearly not driven by international needs, global relevance, or informing the future. Qualified researchers from developed nations interested in integrative disturbance research have arguably not adequately attended to the processes of international engagement, respected cultural competency, or considered the importance of global literacy.

My intent with this heterodox exposition is to bring to light the need to better understand the responses of human and natural systems to large scale disturbances by encouraging expanded Pacific research. Building such a commitment from scientists in developed countries may increase if the global community embraces the notion that residents of island nations in Oceania will be the first to suffer from the consequences of global climate change, yet they are not among the global residents most responsible for climate change. These residents need to trust that other countries are taking responsibility, and an increase in international interest in applying cutting-edge research skills to "their" TCs may increase that trust.

Researchers from affluent nations may lack the knowledge required to initiate the process of partnering with a resident scientist from a developing nation. That naivety may be intimidating and lead to general lack of interest. Conversely, resident scientists in most developing island nations are burdened by many factors that limit their research capacity, such as minimal funds, lack of institutional support, lack of encouragement from colleagues, and lack of rewards from administrators. Moreover, they may not possess the wherewithal to forge partnerships with scientists from affluent countries, and this may lead to lack of motivation to initiate that process. These mutual hindrances are clearly intimidating, but measures of success that acknowledge the importance of effective learning following TC damage to island ecosystems may be more successfully initiated by scientists from affluent countries.

For example, ecologists in developed countries may increase interest in conducting first-hand research on expeditions (Huigen and Jens, 2006; Schoener and Spiller, 2006; Morrison and Spiller, 2008; Willig et al., 2011; Webb et al., 2014) or conceive studies that partner with resident scientists to collect and publish data (e.g., Gaillard et al., 2007; Sawada et al., 2009; Lin et al., 2011; Marler and Ferreras, 2014). Additionally, when resident scientists do get it right and publish in peer-reviewed journals where the information can be queried in search engines and accessed for perpetuity (e.g., Wu and Kuo, 1999; Yumul et al., 2011), scientists from developed countries need to acknowledge that they will not receive appropriate encouragement from their local colleagues and administrators. Offering greater direct encouragement from the international community to the performing local scientists may foster more subsequent successes. Finally, scientists may align their research with the consortiums like the National Earth System Prediction Capability (http://espc.oar.noaa.gov) and contribute to forums such as the annual Tropical Cyclone Research Forum (http://www.ofcm.gov).

In closing, studying extreme weather events in a manner that informs global trends requires case studies (Peduzzi et al., 2012; Abeli et al., 2014), and meeting these needs for TCs requires increased study of TCs in the Pacific. A profound disconnect between scientific information and management decisions has emerged for the majority of the world's regions that are damaged by TCs because the best science to inform future TC damage management cannot be generated where the majority of TC research has been conducted. Perhaps the extreme focus on Atlantic TCs is logistical, with the TC systems in interested scientist's own back yard being more easily studied. Perhaps it is a result of domestic interest in local issues rather than international interest in global issues. Perhaps it is a result of a zero sum game with global research resources being pulled into a vacuum created by proximity to scientists within the Anglosphere and their ethnocentric control of global resources and agendas. Alternatively, perhaps the costs of doing research in distant locations lead scientists from developed nations to focus on local issues as a means of generating competitive budgets in grant proposals. A shift in channeling sufficient resources by the global donor community to Pacific island research perhaps as set-aside offerings would be a beginning to correct the geographic disparity in research effort. Considering increased accountability needs by global donors, continued focus on affluent continental nations for ongoing TC research arguably ignores that accountability. Continued asymmetric research focus on Atlantic continental TC damage is unlikely to deliver the desired outcomes that will directly inform future Atlantic TC events after Atlantic ecosystems have adapted to more frequent TCs. Therefore, if the goal of contemporary TC research is to recalibrate global knowledge of socio-ecological system resistance and resilience in relation to large-scale disturbances and to rethink future restoration or management toolkits, then neophyte biologists and expert disturbance ecologists alike may acknowledge that continued focus on Atlantic TCs at the expense of Pacific TCs cannot foster competency in global efforts to reach that goal.

\section{REFERENCES}

Abeli, T., Jäkäläniemi, A., and Gentili, R. (2014). Living with extremes: the dark side of global climate change. Plant Ecol. 215, 673-675. doi: 10.1007/s11258014-0373-4

Bankoff, G. (2003). Cultures of Disaster: Society and Natural Hazards in the Philippines. London: Routledge.

Bell, G. D., Halpert, M. S., Schnell, R. C., Higgins, R. W., Lawrimore, J., Kousky, V. E., et al. (2000). Climate assessment for 1999. Bull. Am. Meteorol. Soc. 81, S1-S50. doi: 10.1175/1520-0477(2000)81[s1:CAF]2.0.CO;2

Bender, M. A., Tuleya, R. E., and Kurihara, Y. (1987). A numerical study of the effect of island terrain on tropical cyclones. Mon. Wea. Rev. 115, 130-155.

Bramwell, D., and Caujapé-Castells, J. (eds.). (2011). Biology of Island Floras. Cambridge: Cambridge University Press.

Brooks, T. M., Mittermeier, R. A., da Fonseca, G. A. B., Gerlach, J., Hoffmann, M., Lamoreux, J. F., et al. (2006). Global biodiversity conservation priorities. Science 313, 58-61. doi: 10.1126/science.1127609

Camargo, S. J., and Sobel, A. H. (2005). Western North Pacific tropical cyclone intensity and ENSO. J. Clim. 18, 2996-3006. doi: 10.1175/JCLI 3457.1

Chan, J. C. L. (2000). Tropical cyclone activity over the western North Pacific associated with El Niño and La Niña events. J. Clim. 13, 2960-2972. doi: 10.1175/1520-0442(2000)013<2960:TCAOTW >2.0.CO;2

Chen, X., and Tung, K.-K. (2014). Varying planetary heat sink led to globalwarming slowdown and acceleration. Science 345, 897-903. doi: 10.1126/science. 1254937

Chowdhury, M. D. R., Chu, P.-S., and Guard, C. C. (2014). An improved sea level forecasting scheme for hazards management in the US-affiliated Pacific Islands. Int. J. Climatol. 34, 2320-2329. doi: 10.1002/joc.3841 
Clark, J. D., and Chu, P.-S. (2002). Interannual variation of tropical cyclone activity over the Central North Pacific. J. Meteorol. Soc. Jpn. 80, 403-418. doi: 10.2151/jmsj.80.403

Cole, L. E. S., Bhagwat, S. A., and Willis, K. J. (2014). Recovery and resilience of tropical forests after disturbance. Nat. Commun. 5, 3906. doi: $10.1038 /$ ncomms4906

Connell, J. (2013). Islands at Risk? Environments, Economies and Contemporary Change. Cheltenham: Edward Elgar Pub.

Dale, V. H., Joyce, L. A., McNulty, S., Neilson, R. P., Ayres, M. P., Flannigan, M. D., et al. (2001). Climate change and forest disturbances. Bioscience 51, 723-734. doi: 10.1641/0006-3568(2001)051[0723:CCAFD]2.0.CO;2

Elsner, J. B., Kossin, J. P., and Jagger, T. H. (2010). The increasing intensity of the strongest tropical cyclones. Nature 455, 92-95. doi: 10.1038/nature07234

Emanuel, K. A. (2005). Increasing destructiveness of tropical cyclones over the past 30 years. Nature 436, 686-688. doi: 10.1038/nature03906

Gaillard, J.-C., Liamzon, C. C., and Villanueva, J. D. (2007). 'Natural' disaster? A retrospect into the causes of the late-2004 typhoon disaster in Eastern Luzon, Philippines. Environ. Hazards 7, 257-270. doi: 10.1016/j.envhaz.2006.11.002

Hsu, P.-C., Chu, P.-S., Murakami, H., Zhao, X., and Zhao, X. (2014). An abrupt decrease in the late-season typhoon activity over the Western North Pacific. J. Clim. 27, 4296-4312. doi: 10.1175/JCLI-D-13-00417.1

Huigen, M. G. A., and Jens, I. C. (2006). Socio-economic impact of super typhoon Harurot in San Mariano, Isabela, the Philippines. World Dev. 34, 2116-2136. doi: 10.1016/j.worlddev.2006.03.006

Kim, H.-M., Webster, P. J., and Curry, J. A. (2011). Modulation of North Pacific tropical cyclone activity by three phases of ENSO. J. Clim. 24, 1839-1849. doi: 10.1175/2010JCLI3939.1

Kintisch, E. (2014). Is Atlantic holding earth's missing heat? Science 345, 860-861. doi: 10.1126/science.345.6199.860

Knutson, T. R., McBride, J. L., Chan, J., Emanuel, K., Holland, G., Langsea, C., et al. (2010). Tropical cyclones and climate change. Nat. Geosci. 3, 157-163. doi: 10.1038 /ngeo779

Laurence, W. F., and Bierregaard, R. O. Jr. (1977). Tropical Forest Remnants. Chicago, IL: University Chicago Press.

Lin, T. C., Hamburg, S. P., Lin, K. C., Wang, L. J., Chang, C. T., Hsia, Y. J., et al. (2011). Typhoon disturbance and forest dynamics: lessons from a Northwest Pacific subtropical forest. Ecosystems 14, 127-143. doi: 10.1007/s10021-0109399-1

MacArthur, R. H., and Wilson, E. O. (1963). An equilibrium theory of insular zoogeography. Evolution 17, 373-387. doi: 10.2307/2407089

Marler, T. E. (2001). Tropical cyclones and perennial species in the Mariana Islands. Hortscience 36, 264-268.

Marler, T. E. (2013). Increased threat of island endemic tree's extirpation via invasion-induced decline of intrinsic resistance to recurring tropical cyclones. Commun. Integr. Biol. 6:e22361. doi: 10.4161/cib.22361

Marler, T. E., and Ferreras, U. F. (2014). Differential leaflet mortality may influence biogeochemical cycling following tropical cyclones. Commun. Integr. Biol. 7:e27924. doi: 10.4161/cib.27924

Marler, T. E., and Lawrence, J. H. (2013). Phytophagous insects reduce cycad resistance to tropical cyclone winds and impair storm recovery. Hortscience 48, 1224-1226.

Mittermeier, R. A., Robles, G. P., and Mittermeier, C. G. (1997). Megadiversity, Earth's Biological Wealthiest Nations. Monterrey: CEMEX.

Morrison, L. W., and Spiller, D. A. (2008). Patterns and processes in insular floras affected by hurricanes. J. Biogeogr. 35, 1701-1710. doi: 10.1111/j.13652699.2008.01910.x

Myers, N., Mittermeier, R. A., Mittermeier, C. G., da Fonseca, G. A. B., and Kent, J. (2000). Biodiversity hotspots for conservation priorities. Nature 403, 853-858. doi: $10.1038 / 35002501$

NDRRMC. (2014). Updates re the Effects of Typhoon Yolanda (Haiyan). Quezon City: National Disaster Risk Reduction and Management Center.

Peduzzi, P., Chatenoux, B., Dao, H., De Bono, A., Herold, C., Kossin, J., et al. (2012). Global trends in tropical cyclone risk. Nat. Clim. Change 2, 289-294. doi: $10.1038 /$ nclimate 1410
Persoon, G. A., and van Weerd, M. (2006). Biodiversity and natural resource management in insular Southeast Asia. Isl. Stud. J. 1, 81-108.

Porensky, L. M., and Young, T. P. (2013). Edge-effect interactions in fragmented and patchy landscapes. Conserv. Biol. 27, 509-519. doi: 10.1111/cobi. 12042

Primavera, J. H., and Sabada, R. B. (2012). Beach Forests and Mangrove Associates in the Philippines. Iloilo: Southeast Asian Fisheries Development Center.

Riemer, M., and Jones, S. C. (2010). The downstream impact of tropical cyclones on a developing baroclinic wave in idealized scenarios of extratropical transition. Q. J. R. Meteorol. Soc. 136, 617-637. doi: 10.1002/qj.605

Sales, R. F. M. Jr. (2009). Vulnerability and adaptation of coastal communities to climate variability and sea-level rise: their implications for integrated coastal management in Cavite City, Philippines. Ocean Coast. Manag. 52, 395-404. doi: 10.1016/j.ocecoaman.2009.04.007

Sawada, Y., Estudillo, J. P., Fuwa, N., and Kajisa, K. (2009). "How do people cope with a natural disaster? The case of super typhoon Milenyo in the Philippines," in Development, Natural Resources and the Environment, eds G. P. Carnaje and L. S. Cabanilla (Los Baños: University Philippines), 116-150.

Schelzig, K. (2005). Poverty in the Philippines: Income, Assets, and Access. Manila: Asian Development Bank.

Schoener, T. W., and Spiller, D. A. (2006). Nonsynchronous recovery of community characteristics in island spiders after a catastrophic hurricane. Proc. Natl. Acad. Sci. U.S.A. 103, 2220-2225. doi: 10.1073/pnas.0510355103

Sohmer, S. H. (2001). Conservation lessons from studies in Philippine Psychotria. Malayan Nat. J. 55, 43-47.

Stocker, T. F., Qin, D., Plattner, G.-K., Tignor, M., Allen, S. K., Boschung, J., et al. (eds.). (2013). Summary for Policymakers. Climate Change 2013: The Physical Science Basis. Contribution of Working Group I to the Fifth Assessment Report of the Intergovernmental Panel on Climate Change. Cambridge: Cambridge University Press.

Walker, L. R., Silver, W. L., Willig, M. R., and Zimmerman, J. K. (eds.). (1996). Long term responses of Caribbean ecosystems to disturbance. Biotropica 28, 414-613.

Webb, E. L., van de Bult, M., Fa'Aumu, S., Webb, R. C., Tualaulelei, A., and Carrasco, L. R. (2014). Factors affecting tropical tree damage and survival alter catastrophic wind disturbance. Biotropica 46, 32-41. doi: 10.1111/btp. 12067

Willig, M. R., Presley, S. J., and Bloch, C. P. (2011). Long-term dynamics of tropical walking sticks in response to multiple large-scale and intense disturbances. Oecologia 165, 357-368. doi: 10.1007/s00442-010-1737-7

Wu, C.-C., and Kuo, Y.-H. (1999). Typhoons affecting Taiwan: current understanding and future challenges. Bull. Am. Meteorol. Soc. 80, 67-80.

Yumul, G. P., Cruz, N. A., Servando, N. T., and Dimalanta, C. B. (2011). Extreme weather events and related disasters in the Philippines, 2004-08: a sign of what climate change will mean? Disasters 35, 362-382. doi: 10.1111/j.14677717.2010.01216.x

Conflict of Interest Statement: The author declares that the research was conducted in the absence of any commercial or financial relationships that could be construed as a potential conflict of interest.

Received: 09 August 2014; accepted: 23 September 2014; published online: 13 October 2014.

Citation: Marler TE (2014) Pacific island tropical cyclones are more frequent and globally relevant, yet less studied. Front. Environ. Sci. 2:42. doi: 10.3389/fenvs. 2014.00042

This article was submitted to Interdisciplinary Climate Studies, a section of the journal Frontiers in Environmental Science.

Copyright (C) 2014 Marler. This is an open-access article distributed under the terms of the Creative Commons Attribution License (CC BY). The use, distribution or reproduction in other forums is permitted, provided the original author(s) or licensor are credited and that the original publication in this journal is cited, in accordance with accepted academic practice. No use, distribution or reproduction is permitted which does not comply with these terms. 